IFC - Bank Indonesia International Workshop and Seminar on "Big Data for Central Bank Policies / Building Pathways for Policy Making with Big Data"

Bali, Indonesia, 23-26 July 2018

\title{
Nowcasting private consumption: traditional indicators, uncertainty measures, credit cards and some internet data ${ }^{1}$
}

\author{
María Gil, Javier J. Pérez and Alberto Urtasun, \\ Bank of Spain
}

A. Jesus Sánchez, Complutense University of Madrid

1 This paper was prepared for the meeting. The views expressed are those of the authors and do not necessarily reflect the views of the BIS, the IFC or the central banks and other institutions represented at the meeting. 


\title{
Nowcasting private consumption: traditional indicators, uncertainty measures, credit cards and some internet data ${ }^{1}$
}

\author{
María Gil, Javier J. Pérez, A. Jesús Sánchez and Alberto Urtasun
}

The focus of this paper is on nowcasting and forecasting quarterly private consumption. The selection of real-time, monthly indicators focuses on standard ("hard" / "soft" indicators) and less-standard variables. Among the latter group we analyze: i) proxy indicators of economic and policy uncertainty; ii) payment cards' transactions, as measured at "Point-ofsale" (POS) and ATM withdrawals; iii) indicators based on consumption-related search queries retrieved by means of the Google Trends application. We estimate a suite of mixed-frequency, time series models at the monthly frequency, on a real-time database with Spanish data, and conduct out-ofsample forecasting exercises to assess the relevant merits of the different groups of indicators. Some results stand out: i) "hard" and payments cards indicators are the best performers when taken individually, and more so when combined; ii) nonetheless, "soft" indicators are helpful to detect qualitative signals in the nowcasting horizon; iii) Google-based and uncertainty indicators add value when combined with traditional indicators, most notably at estimation horizons beyond the nowcasting one, what would be consistent with capturing information about future consumption decisions; iv) the combinations of models that include the best performing indicators tend to beat broader-based combinations.

1 This article summarises the main ideas and results reported in Gil, M.; Pérez, J.J.; Sánchez, A.J. y Urtasun, A (2018): "Nowcasting private consumption: traditional indicators uncertainty measures, credit cards and some internet data". Working Paper 1842, Banco de España.

[https://www.bde.es/f/webbde/SES/Secciones/Publicaciones/PublicacionesSeriadas/DocumentosTra bajo/18/Files/dt1842e.pdf] 


\section{Introduction}

Benchmark data to approximate private households' spending decisions are normally provided by the national accounts, and are available at the quarterly frequency. Nevertheless, usually, there exists a significant publication lag, typically of 90 days after the quarter of reference ended. More timely data is usually available in the form of economic indicators. In our paper, from a forecasting point of view, we analyze the information content of new sources of information, but in a context in which we ascertain their value in conjunction with traditional, more proven, sources of shortterm information, such as the "hard" and "soft" ones mentioned above. In particular, among these new data sources we look, first, at data collected from automated teller machines (ATMs), encompassing cash withdrawals at ATM terminals, and points-ofsale (POS) payments with debit and credit cards, given the increasing and widespread use of electronic payment systems by economic agents. Secondly, in line with a recent and very active branch of the literature, we construct indicators of consumption behavior on the basis of internet search patterns as provided by Google Trends. Finally, we use measures of economic and policy uncertainty, in line with another recent strand of the literature that has highlighted the relevance of the level of uncertainty prevailing in the economy for private agents' decision-making.

To exploit the data in an efficient and effective manner, we build models that relate data at the quarterly and monthly frequencies. We follow the modeling approach of Harvey and Chung (2000).3 The mixture of frequencies, and the estimation of models at the monthly frequency, implies combining variables that at the monthly frequency can be considered as stocks with those being pure flows. The quarterly private consumption series cast into the monthly frequency is a set of missing observations for the first months of the quarter (January and February, in the case of Q1) and the observed value assigned to the last month of each quarter (say, March). Theoretically, the quarterly National Accounts series would be obtained from monthly National Accounts series by aggregation of the three months of a quarter (January to March) had them been available. We estimate such mixed-frequency models on a mixed real-time and pseudo-real-time database, for the period that starts in the early 2000s and runs through to 2017Q4, and conduct out-of-sample forecasting exercises to assess the relevant merits of different groups of indicators.

\section{The empirical exercise}

We build up a real-time database for the target variable, quarterly private consumption as measured by the National Accounts, for the period 1995Q1-2017Q4. The size of the sample for our empirical exercises, though, is restricted by the availability of some of the monthly indicators, in particular as regards Google Trends, the EPU index, and the Services Sector Activity Indicator, available for the sample starting in January 2004, January 2001, and January 2002, respectively. As regards the indicator variables we could not replicate a truly real-time dataset, so we proceeded to built up a pseudo real-time one, namely we adjusted for each point in time (month) the information set that had been available given the timing rules that we describe in the next paragraph. It is worth mentioning that the indicators that we use are not revised, which means that the pseudo-real-time approximation should be a fair representation of data available in real-time. The only discrepancy may arise from 
seasonal-adjustment. While we seasonally-adjust the series that are published on nonseasonally-adjusted terms following our pseudo-real-time approach, we take official series that are published in a seasonally-adjusted form as the latest available vintage of official data.

In order to test the relevant merits of each group of indicators, as mentioned above, we consider several models that differ in the set of indicators included in each one. We estimate models that include indicators from each group at a time, several groups at a time, and different combinations of individual models.

As a mechanical benchmark we use a random walk model, whereby we repeat in future quarters the latest quarterly growth rate observed for private consumption.

We focus on the forecast performance at the nowcasting horizon (current quarter), but also explore forecasts at 1 to 4 quarters-ahead from each one of the current quarter forecast origins (first month of the quarter, second and third).

\section{Results}

First, from table1 1 (relative RMSEs) the following results can be highlighted. As regards models that use only indicators from each group (first panel of the table), the ones that use quantitative indicators and payment cards (amounts) tend to perform best than the others at the nowcasting and, somewhat less so, forecasting (1-quarterand 4-quarters-ahead) horizons. Relative RMSE are in almost all cases below one, even though from a statistical point of view they are only different from quarterly random walk nowcasts and forecasts in a few instances. In general, the other models do not beat systematically the quarterly random walk alternative. The two main exceptions are the model with qualitative indicators for the nowcasting horizons, and the Google-Trends based ones for the longer-horizon forecasts. The latter results might be consistent with the prior that Google-based indicators deliver today information on steps to prepare purchases in the future. Lastly, it is worth mentioning that nowcast/forecast accuracy does not always improve monotonically as the information set expands, i.e. as we move from nowcast/forecast origins $\mathrm{m} 1$ (first month) to $\mathrm{m} 3$ (third month). This is explained by the real-time nature of the information set used in each case. Following the standard publication calendar, at $\mathrm{m} 2$-time the quarterly figure of private consumption corresponding to the previous quarter is published. This has two implications. On the one hand, the quarterly random walk alternative moves from a situation in which the reference was the $t-2$ figure to one in which the $t-1$ quarter is used. On the other hand, quarterly data corresponding to previous quarters tend to be revised at $\mathrm{m} 2$, which may affect the estimation of models in real-time, and eventually the accuracy of the generated nowcasts/forecasts, or at least the comparability of estimations based on different information sets. The revision of past, quarterly national accounts figures is quite apparent when going through the different panels of figures 3 and 4 in a chronological order.

Second, in the middle panel of Table 1 we show the results of the estimation of models that include quantitative indicators while adding, in turn, variables from the other groups (qualitative, payment cards - amounts, uncertainty, Google-Trendsbased). The improvement in nowcast accuracy is not generalized when adding more indicators, with the exception of the "soft" ones ( $\mathrm{m} 1$ and $\mathrm{m} 3$ origins). Nonetheless, 
there is a significant improvement for longer forecast horizons of expanding the baseline model. In particular, for the 4-quarters-ahead one, uncertainty and Googlebased indicators add significant value to the core "hard"-only based model.

Finally, as regards the third panel of results of Table 1, it seems clear that the combination (average) of models with individual groups of indicators improves the forecasting performance in all cases and at all horizons. Most notably, the combination of the forecasts of models including quantitative indicators with those with payment cards (amounts), delivers, in general, the best nowcasting/forecasting performance at all horizons. At the same time, adding the "soft" forecasts seems to add value in the nowcasting phase, when more information for the current quarter is available ( $\mathrm{m} 2$ and $\mathrm{m} 3$ origins). In turn, the combination of a broad set of models (first line of the panel) produces the lowest RMSE relative to the quarterly random walk at the four quarters ahead forecast horizon. Nevertheless, the bilateral DM-test results with respect to combinations of simpler models do not tend to be, in general, significantly different from zero from a statistical point of view. In addition, according to this metric, also the models with only quantitative, qualitative and payment cards indicators individually, beat the combination of the broad set of models at the nowcasting horizons.

\section{Conclusions}

We estimate a suite of mixed-frequency models on an (almost) real-time database for the period January 2001 - December 2017, and conduct out-of-sample forecasting exercises to assess the relevant merits of different groups of indicators. The selection of indicators is guided by the standard practice ("hard" and "soft" indicators), but also expand this practice by looking at non-standard variables, namely: (i) a suite of proxy indicators of uncertainty, calculated at the monthly frequency; (ii) two additional sets of variables that are sampled at a much lower frequency: payment card transactions and indicators based on search query time series provided by Google Trends. The latter set of indicators is based on factors extracted from consumption-related search categories of the Google Trends application.

Our study shows that, even though traditional indicators make a good job at nowcasting and forecasting private consumption in real-time, novel data sources add value, most notably those based on payment cards-related, but also, to a lesser extent, Google-based and uncertainty indicators when combined with other sources. 
Table 1: Relative RMSE statistics: ratio of each modelo to the quarterly random walk. ${ }^{a}$

\begin{tabular}{|c|c|c|c|c|c|c|c|c|c|}
\hline \multicolumn{10}{|c|}{ Models including inidcators of only one group } \\
\hline & \multicolumn{3}{|c|}{ Nowcast } & \multicolumn{3}{|c|}{ 1-q-ahead } & \multicolumn{3}{|c|}{ 4-q-ahead } \\
\hline & $\mathrm{m} 1$ & $\mathrm{~m} 2$ & $\mathrm{~m} 3$ & $\mathrm{~m} 1$ & $\mathrm{~m} 2$ & $\mathrm{~m} 3$ & $\mathrm{~m} 1$ & $\mathrm{~m} 2$ & $\mathrm{~m} 3$ \\
\hline Quantitative ("hard") indicators ${ }^{\mathrm{b}}$ & 0.84 & $0.75^{*}$ & 0.79 & $0.75^{\star \star}$ & 0.81 & 0.80 & 0.98 & 0.97 & 1.00 \\
\hline Qualitative ("soft") indicators ${ }^{c}$ & 1.01 & 0.85 & 0.85 & 1.11 & 1.05 & 1.05 & 1.09 & 1.10 & $1.29^{*}$ \\
\hline Payment cards (amounts, am) ${ }^{d}$ & 0.79 & 0.82 & 0.88 & $0.65^{\star \star \star}$ & 0.84 & $0.69^{* *}$ & $0.74^{\star *}$ & 0.84 & 0.83 \\
\hline Payment cards (numbers) ${ }^{d}$ & 1.05 & 1.15 & 1.13 & 0.90 & 1.10 & 0.98 & $0.75^{* \star}$ & 0.81 & 0.79 \\
\hline Uncertainty indicators ${ }^{e}$ & 1.06 & 0.97 & 0.99 & 1.00 & 1.05 & 1.06 & 0.94 & 1.00 & 1.02 \\
\hline Google: aggregate of all indicators & 1.04 & 1.06 & 1.06 & 0.85 & 1.03 & 1.03 & $0.71^{\star *}$ & 0.79 & 0.79 \\
\hline Google: durable goods (lagged) & 1.04 & 0.97 & 0.98 & 0.96 & 1.04 & 1.04 & $0.85^{*}$ & 0.93 & 0.93 \\
\hline
\end{tabular}

\begin{tabular}{|c|c|c|c|c|c|c|c|c|c|}
\hline \multicolumn{10}{|c|}{ Models including indicators from different groups } \\
\hline & \multicolumn{3}{|c|}{ Nowcast } & \multicolumn{3}{|c|}{ 1-q-ahead } & \multicolumn{3}{|c|}{ 4-q-ahead } \\
\hline & $\mathrm{m} 1$ & $\mathrm{~m} 2$ & $\mathrm{~m} 3$ & $\mathrm{~m} 1$ & $\mathrm{~m} 2$ & m3 & $\mathrm{m} 1$ & $\mathrm{~m} 2$ & $\mathrm{~m} 3$ \\
\hline Quantitative \& Qualitative & $0.69^{* *}$ & 0.78 & 0.77 & $0.67^{\star \star \star}$ & $0.76^{*}$ & $0.72^{*}$ & $0.79^{*}$ & $0.82^{*}$ & $0.80^{*}$ \\
\hline Quantitative \& Payment cards $(\mathrm{am}) \mathrm{d}$ & 0.90 & 0.82 & 0.91 & $0.67^{\star \star \star}$ & 0.79 & 0.78 & 0.86 & 0.89 & 0.91 \\
\hline Quantitative \& Uncertainty & 0.88 & 0.86 & 0.75 & $0.74^{* *}$ & 0.91 & 0.93 & $0.69^{* *}$ & 0.76 & 0.76 \\
\hline Quantitative \& Google (aggregate) & 0.85 & 0.76 & 0.77 & $0.81^{*}$ & 0.94 & 0.89 & $0.77^{* *}$ & $0.81^{*}$ & 0.82 \\
\hline Quantitative \& Google (durables) & 0.91 & 0.95 & 0.87 & $0.69^{* \star}$ & 0.83 & 0.88 & $0.72^{\star \star}$ & $0.76^{*}$ & $0.77^{\star}$ \\
\hline
\end{tabular}

\begin{tabular}{|c|c|c|c|c|c|c|c|c|c|}
\hline \multicolumn{10}{|l|}{ Combination of models } \\
\hline & \multicolumn{3}{|c|}{ Nowcast } & \multicolumn{3}{|c|}{ 1-q-ahead } & \multicolumn{3}{|c|}{ 4-q-ahead } \\
\hline & $\mathrm{m} 1$ & $\mathrm{~m} 2$ & $\mathrm{~m} 3$ & $\mathrm{~m} 1$ & $\mathrm{~m} 2$ & $\mathrm{~m} 3$ & $\mathrm{~m} 1$ & $\mathrm{~m} 2$ & $\mathrm{~m} 3$ \\
\hline All models ${ }^{f}$ & $0.66^{* *}$ & $0.71^{* *}$ & $0.69^{* *}$ & $0.68^{* *}$ & $0.77^{\star}$ & $0.68^{* *}$ & $0.73^{* *}$ & $0.78^{*}$ & $0.78^{*}$ \\
\hline Hard \& Payment cards $(\mathrm{am}) \mathrm{d}$ & $0.62^{* *}$ & $0.69^{* *}$ & $0.71^{* \star}$ & $0.53^{* \star}$ & $0.69^{* *}$ & $0.52^{* \star *}$ & $0.79^{*}$ & 0.86 & 0.84 \\
\hline Hard, Payment cards (am)d \& Soft & $0.65^{* *}$ & $0.67^{* *}$ & $0.67^{* \star}$ & $0.68^{* \star}$ & $0.74^{\star *}$ & $0.59^{* \star *}$ & $0.83^{*}$ & 0.89 & 0.92 \\
\hline Hard \& Soft & $0.68^{* *}$ & $0.66^{* \star}$ & $0.66^{* \star}$ & $0.77^{* *}$ & $0.75^{\star *}$ & $0.69^{\star *}$ & 0.91 & 0.94 & 1.02 \\
\hline Hard \& Google (durables) & $0.77^{* *}$ & $0.78^{* *}$ & $0.76^{* *}$ & $0.74^{* *}$ & 0.83 & $0.78^{*}$ & 0.85 & 0.91 & 0.9 \\
\hline
\end{tabular}

Hard \& Google (durables)

$0.77^{* *}$

$0.78^{* *}$

Notes:

The asterisks denote the Diebold Mariano test results for the null hypothesis of equal forecast accuracy of two forecast methods. A squared loss function is used. The number in each cell represents the loss differential of the method in its horizontal line as compared to the quarterly random walk alternative. A single (double) [triple] asterisk denotes rejection of the null hypothesis at the $10 \%(5 \%)[1 \%]$ level of significance. of the null hypothesis at the $10 \%(5 \%)[1 \%]$ level of significance.

${ }^{\text {a }}$ Nowcast/forecast errors computed as the difference to the first released vintage of private consumption data. Forecasts generated recursively over the moving window 2008Q1 (m1) to 2017Q4 (m3)

${ }^{\mathrm{b}}$ Social Security Registrations; Retail Trade Index; Activity Services Index.

${ }^{\mathrm{C}}$ PMI Services; Consumer Confidence Index.

${ }^{\mathrm{d}}$ Aggregate of payment cards via POS and ATMs.

e Stock Market Volatility (IBEX); Economic Policy Uncertainty Index (EPU)

${ }^{f}$ Combination of the results of 30 models, that include models in which the indicators of each block are included separately, models that include the quantitative block and each other block, and version of all the previous models but including lags of the variables. 
IFC - Bank Indonesia International Workshop and Seminar on "Big Data for Central Bank Policies / Building Pathways for Policy Making with Big Data"

Bali, Indonesia, 23-26 July 2018

\section{Nowcasting private consumption: traditional indicators, uncertainty measures, credit cards and some internet data ${ }^{1}$}

María Gil, Javier J. Pérez and Alberto Urtasun,

Bank of Spain

A. Jesus Sánchez,

Complutense University of Madrid

1 This presentation was prepared for the meeting. The views expressed are those of the authors and do not necessarily reflect the views of the BIS, the IFC or the central banks and other institutions represented at the meeting. 


\section{Nowcasting private consumption: traditional indicators, uncertainty measures, credit cards and some internet data}

María Gil, Javier J. Pérez (*), and Alberto Urtasun

Bank of Spain, Eurosystem

\section{A. Jesus Sánchez}

Univ. Complutense of Madrid, Spain

Bank Indonesia / IFC "International Workshop on Big Data for Central Bank Policies"

Bali, Indonesia, 25 July 2018 
Outline

\section{Motivation}

2. Literature review

3. The data

4. Modeling approach

5. The empirical exercise

6. Selection of results and conclusions 


\section{Motivation}

- Relevance of private consumption: some $60 \%$ of GDP

- Key variable from both a forecasting and a policy perspective

- Real-time assessment limited by availability of statistical information (QNA and monthly, traditional indicators, subject to standard publication lags)

\section{Example: Nowcasting of q-q growth rates of QNA private consumption in the first quarter of 2017 (Spain)}

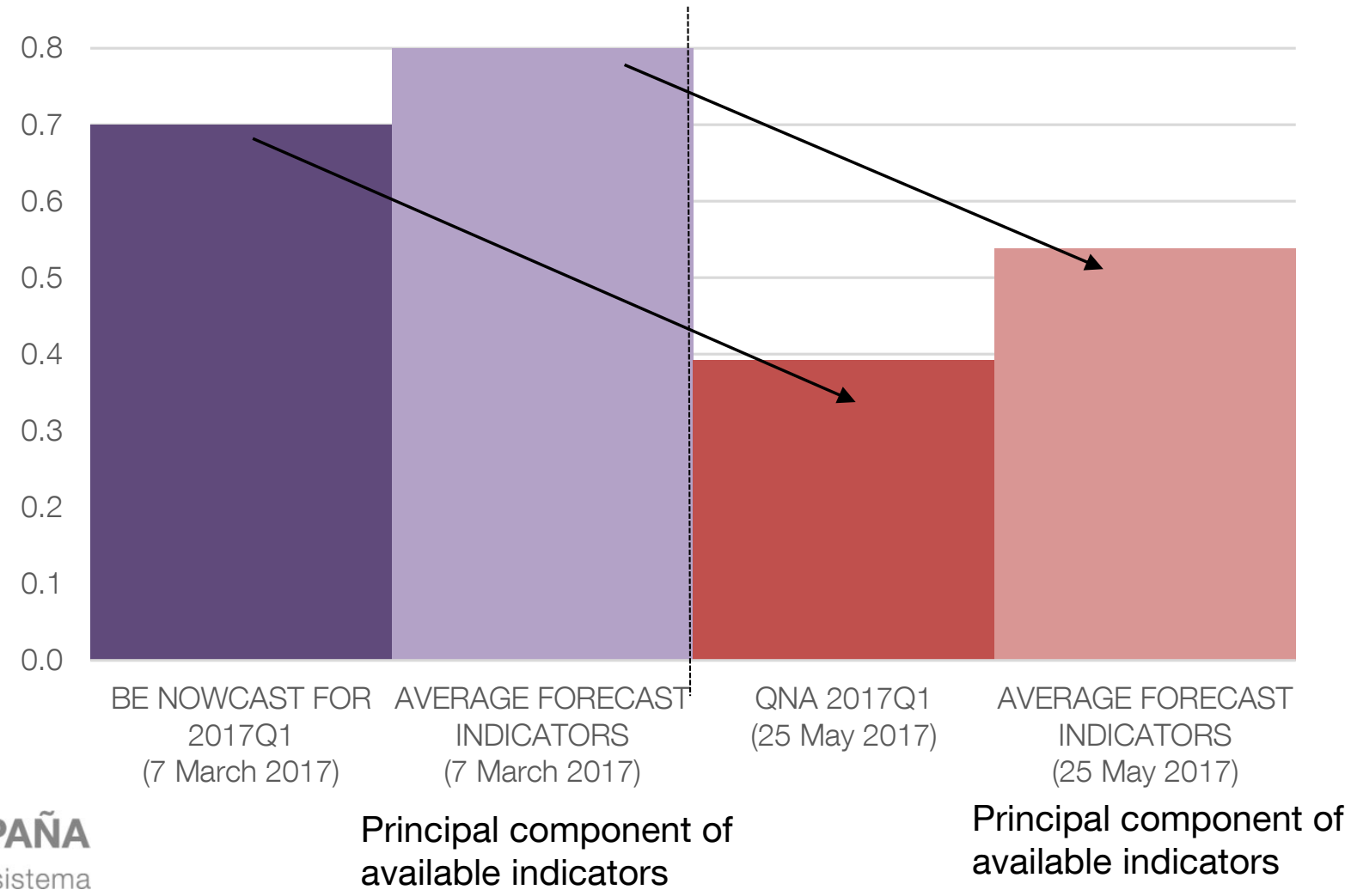


- Technological developments allow the use of new data sources

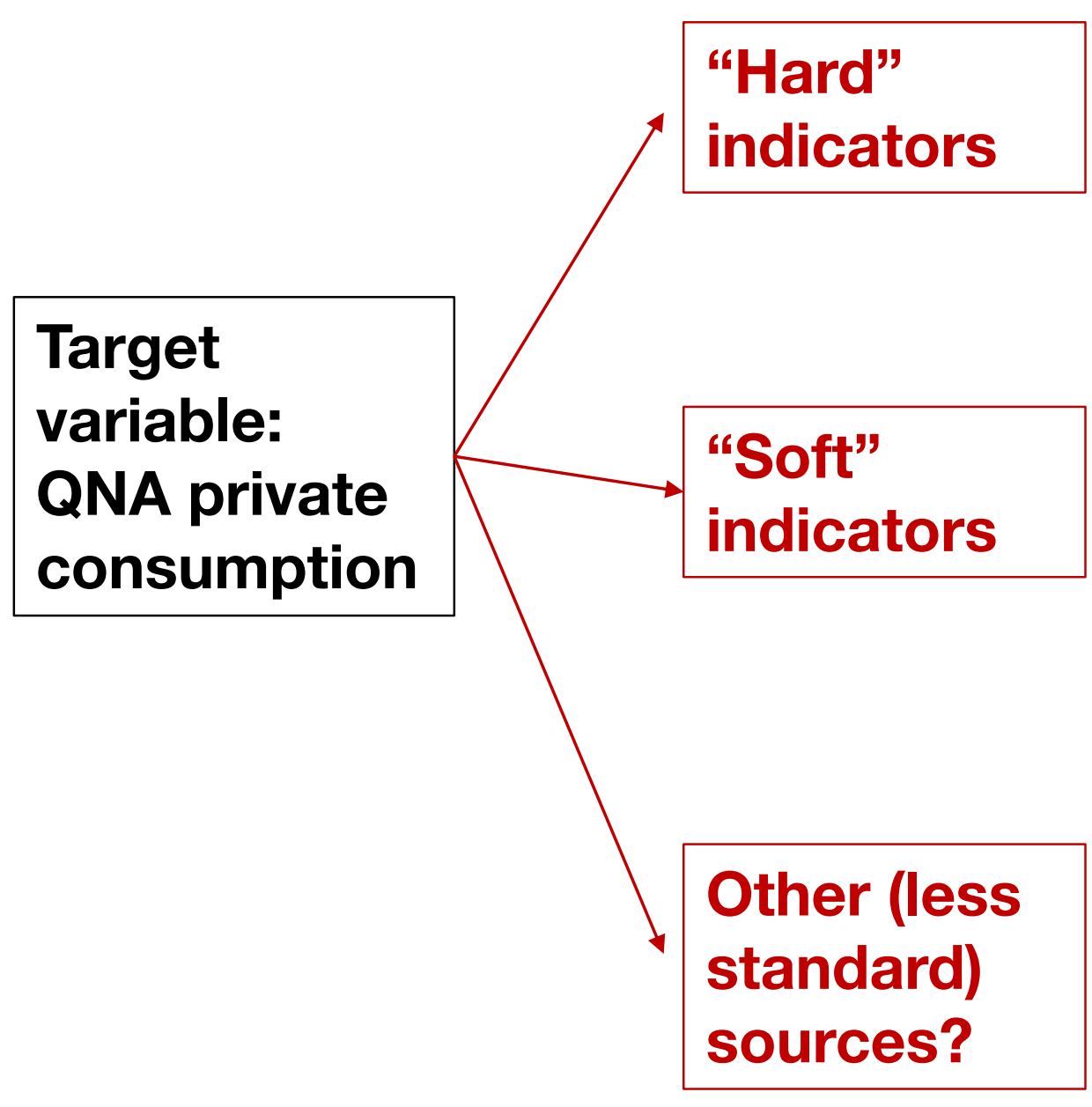

- Available at the monthly frequency ... but released with significant lags

- More timely

- Contemporaneous, leading or lagging behavior?

- Credit cards' spending / withdrawals

- Indicators of "uncertainty"

- Google searches

- $\quad$... 


\section{AIM OF THE PAPER:}

Explore the relative merits of...

... hard vs. soft

... traditional vs. "new" indicators

to "nowcast" Spanish real private consumption 
Outline

1. Motivation

2. Literature review

3. The data

4. Modeling approach

5. The empirical exercise

6. Selection of results and conclusions 


\section{Literature review}

- Traditionally, the literature on "nowcasting" has been quite focused on GDP

- Few exceptions of papers in which GDP is modelled together with its demand and/or supply components

- More recently, the literature has started to explore "new" sources

$\checkmark$ Not so much for the case of private consumption

$\checkmark$ GOOGLE SEARCHES

$\checkmark$ ATM/Point Of Sale DATA

$\checkmark$ UNCERTAINTY MEASURES 
Outline

1. Motivation

2. Literature review

3. The data

4. Modeling approach

5. The empirical exercise

6. Selection of results and conclusions 


\section{The data}

- Quarterly private consumption,

monthly indicators (lower frequencies not exploited yet)

Quarterly private consumption

Social sec. registrations

Retail trade index Services activity index

PMI - services

Consumers confidence index

Credit/debit cards' payments

Amounts

Number

Un

Economic Policy Uncertainty

IBEX-35 volatility index

Google Trends

- Durables

- Non durables
ATM/POS

Uncertainty

"Traditional" indicators

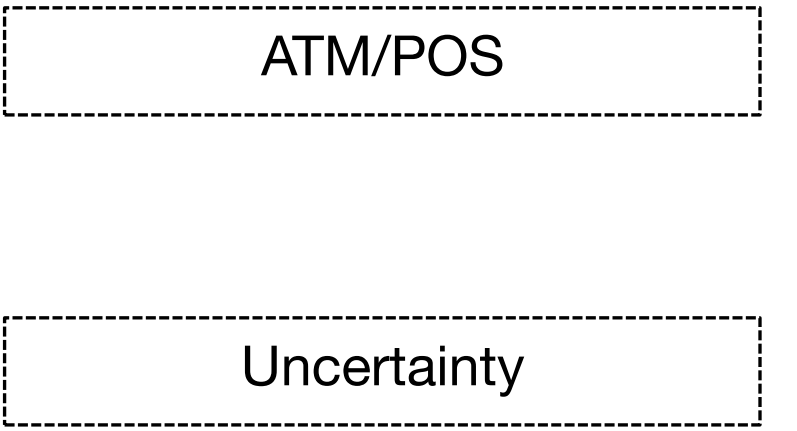

Google search queries 


\section{The data}

- Quarterly private consumption,

Data revisions

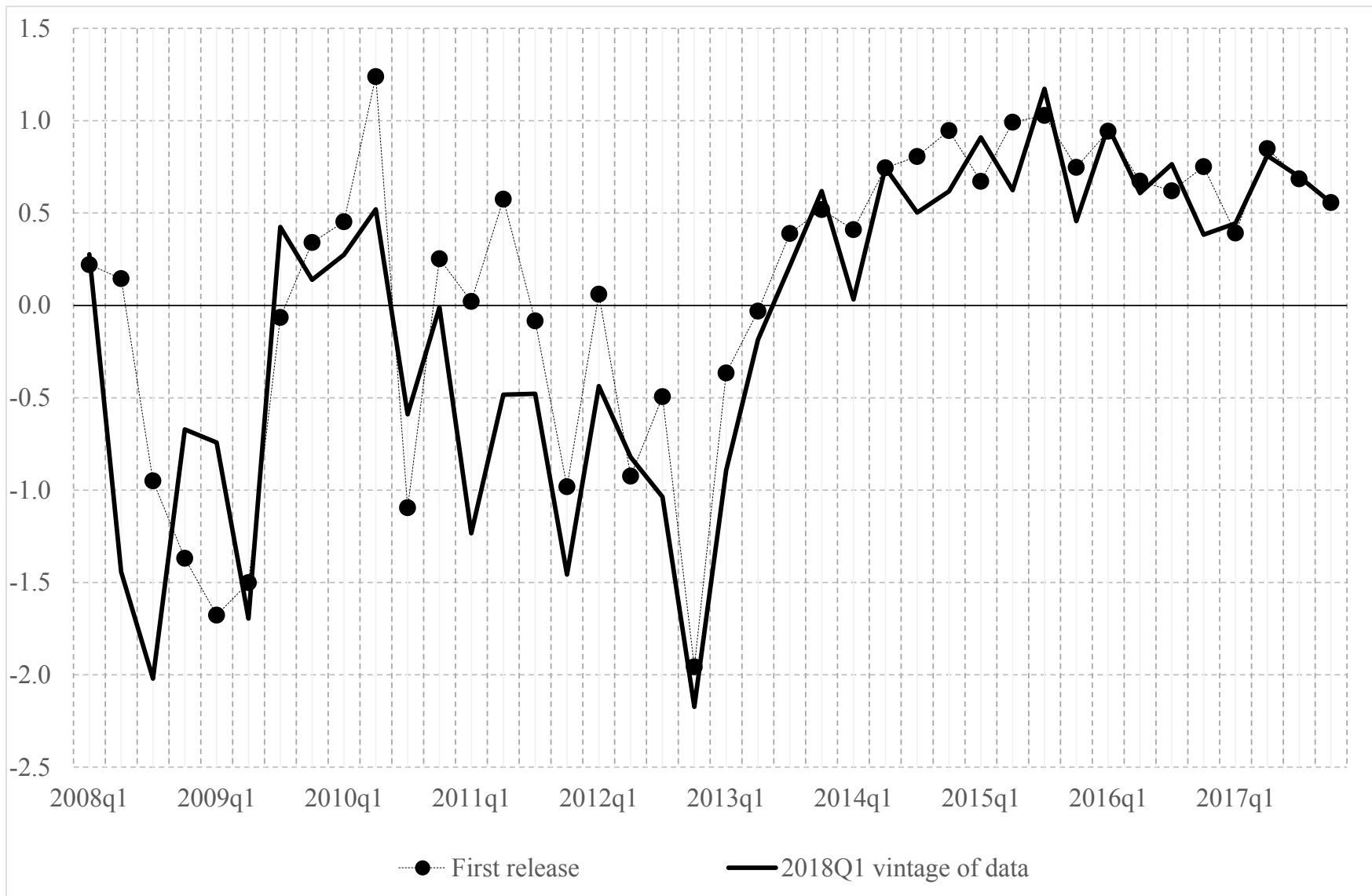




\section{The data: ATM/POS}

- Widespread use of electronic payment systems

- Timeliness [daily/weekly frequency, in theory]

- Credit cards:

- POS: payments by means of credit/debit cards in points of sales amounts [seasonally adjusted, deflated by national CPI] and number of operations

- ATMs: cash withdrawals and number of withdrawls

\section{CREDIT/DEEIT CARDS - POS+ATM AMOUNTS}

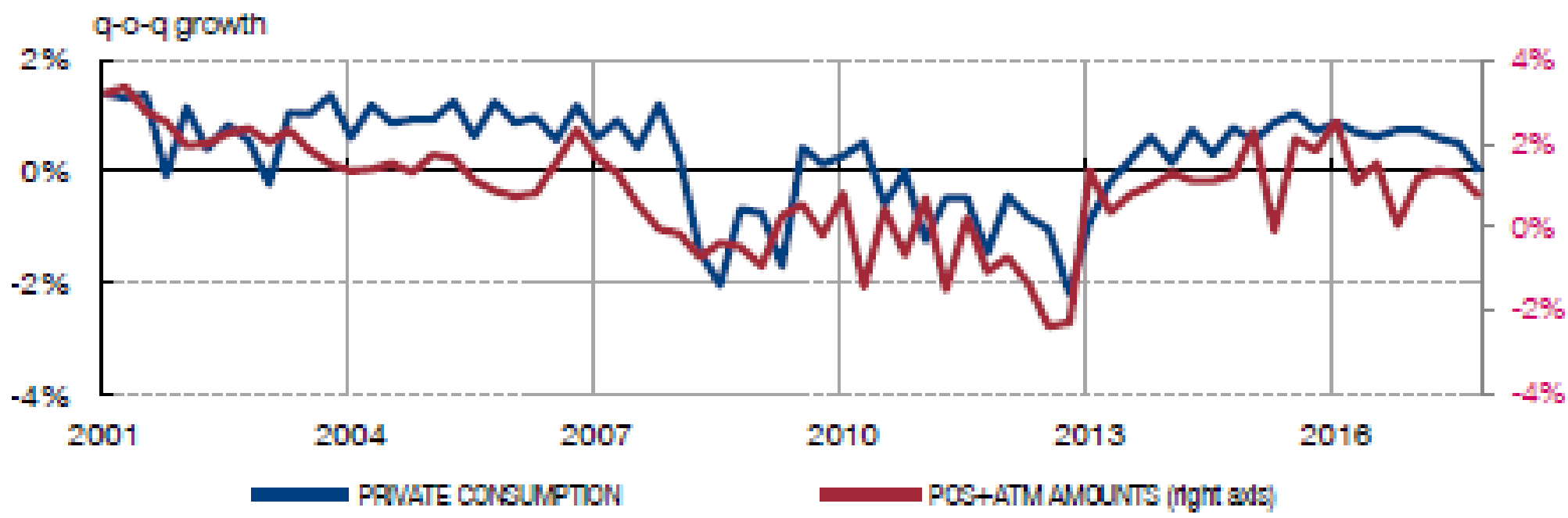




\section{The data: Google Trends}

- Households use internet to buy goods and services

$\checkmark$ Willingness to buy

$\checkmark$ Info easily available.

- Evidence of usefulness in the literature: robustness?

- "Google Trends" provides an index of the relative volume of search queries conducted through Google (daily/weekly)

$\checkmark$ It provides aggregated indexes of search queries which are classified into categories and sub-categories using an automated classification engine

$\checkmark$ We select consumption-relevant categories ( 60) that match the product categories of personal consumption expenditures of the BEA's national income and product accounts 


\section{The data: Google Trends}

- Example

\section{Classification by national product and incc}

\section{Durable goods}

Motor vehicles and parts

Furnishing and durable household equipment

Recreational goods and vehicles

Other durable goods

\section{Google categories}

Automotive, auto financing, automotive parts, auto insurance, Seat, Mercedes Benz, Mercedes offer, second hand car, car, to buy a car Electrical appliance, home insurance, home remodel, home furnishing, interior decoration, interior design

Online movie, to buy a movie, watch online movie, video games

Telecommunications, router wifi, mobile phone, electronic book, novel

- Data available since January 2004 [not seasonally adjusted $\rightarrow$ TRAMO-SEATS]

- Distinguish durable/ non durable/ services

$\checkmark$ "Aggregation": (i) Principal Components Analysis (literature); (ii) NA weights 


\section{The data: Uncertainty}

- Economic Policy Uncertainty Index (EPU) (Baker, Bloom, Davis, 2016): it measures the frequency of news related to economic policy uncertainty in two of the most popular Spanish newspapers.

- European Commission Business and Consumer Surveys: "unemployment expectations for the next 12 months", indicator computed as

$$
\sqrt{\text { Frac }_{t}{ }^{+}+\text {Frac }_{t}{ }^{-}-\left(\text {Frac }_{t}{ }^{+}-\text {Frac }_{t}^{-}\right)^{2}}
$$

where $\mathrm{Fract}^{+/-}$is the weighted fraction of consumers in the cross section with increase/decrease responses at time $t$.

- Indicators of disagreement about consumption and inflation forecasts, calculated using the information provided by a private institute (FUNCAS) that published every two months a panel of forecasters. At each point in time, this measure is computed as the standard deviation of such cross-section of forecasters

$$
\frac{1}{n} \sum_{1}^{n}\left(\hat{\mathrm{C}}_{i}-\hat{\mathrm{C}}_{A}\right)^{2}
$$




\section{The data}

\section{- Preliminary exploration: regressions of $\Delta \log C$ on determinants and indicators}

$\checkmark$ Indicators by blocks add value

$\Delta \log \left(C_{t}\right)=\alpha_{1}+\alpha_{2} \Delta \log \left(C_{t-1}\right)+\alpha_{3} X_{t}+\epsilon_{t}$

\begin{tabular}{|c|c|c|c|c|c|c|c|}
\hline $\begin{array}{l}\text { p-values } \\
\text { Sample: 2001Q1-2016Q4 }\end{array}$ & {$[1]$} & {$[2]$} & {$[3]$} & {$[4]$} & {$[5]$} & {$[6]$} & {$[7]$} \\
\hline $\begin{array}{l}\text { Constant } \\
\text { Interest rate: Euribor } 3 \text {-months }{ }^{a} \\
\text { Households' disposable income }{ }^{b} \\
\text { Lagged } \Delta \log \left(C_{t}\right)\end{array}$ & $\begin{array}{l}0.060^{*} \\
0.635 \\
0.952 \\
0.772\end{array}$ & $\begin{array}{l}0.052^{* *} \\
0.674 \\
0.564 \\
0.100^{*}\end{array}$ & $\begin{array}{l}0.000^{* * *} \\
0.829^{* *} \\
0.267 \\
0.002^{* * *}\end{array}$ & $\begin{array}{l}0.047^{* *} \\
0.513 \\
0.338 \\
0.000^{* * *}\end{array}$ & $\begin{array}{l}0.288 \\
0.370 \\
0.265 \\
0.000^{* * *}\end{array}$ & $\begin{array}{l}0.280 \\
0.523 \\
0.761 \\
0.660\end{array}$ & $\begin{array}{l}0.001^{* * *} \\
0.782 \\
0.487 \\
0.2969\end{array}$ \\
\hline $\begin{array}{l}\text { Short-term Indicators: } \\
\text { "Hard": Social Security Registrations }{ }^{b} \\
\text { "Hard": Retail Trade Index }{ }^{b} \\
\text { "Soft": PMI-Services }{ }^{c} \\
\text { "Soft": Consumers' Confidence Index }{ }^{c} \\
\text { Credit cards: POS amounts (real) }{ }^{b} \\
\text { Credit cards: POS number of transactions } \\
\text { Uncertainty: Stock market volatility }{ }^{c} \\
\text { Uncertainty: Economic Policy }{ }^{b} \\
\text { Google Trends: Durable Goods }{ }^{b} \\
\text { Google Trends: Non-durable Goods }{ }^{b}\end{array}$ & $\begin{array}{l}0.000^{* * *} \\
0.020^{* *}\end{array}$ & $\begin{array}{l}0.007^{* * *} \\
0.162\end{array}$ & $\begin{array}{l}0.003^{* * *} \\
0.252\end{array}$ & $\begin{array}{l}0.0951^{*} \\
0.0000^{* * *}\end{array}$ & $\begin{array}{l}0.037^{* *} \\
0.207^{*}\end{array}$ & $\begin{array}{l}0.010^{* *} \\
0.258 \\
0.007^{* * *} \\
0.872 \\
0.192\end{array}$ & $\begin{array}{l}0.000^{* * *} \\
0.000^{* * *} \\
0.970^{* *} \\
0.086^{*}\end{array}$ \\
\hline R-squared statistic & 0.72 & 0.62 & 0.60 & 0.51 & 0.49 & 0.74 & 0.71 \\
\hline
\end{tabular}

Notes:

a. Deviation from trend (HP-filter).

b. $\Delta \log (\bullet)$.

c. Variable in levels.

d. $\Delta(\bullet)$. 
Outline

1. Motivation

2. Literature review

3. The data

4. Modeling approach

5. The empirical exercise

6. Selection of results and conclusions 


\section{Modelling approach}

- Different sampling frequency: monthly (indicators), quarterly (consumption)

- Publication delays cause missing values for some of the variables at the end of the sample ("ragged-end" problem) 


\section{Modelling approach}

- Mixed-frequencies models, in the vein of Harvey and Chun (2000)

$\checkmark$ Multivariate setup: Unobserved Components Model

- Flexibility: aggregation and modelling using the State Space representation

- Models in levels: no need to worry about ex ante stationarity or cointegration

$\checkmark$ Seemingly Unrelated Structural Time Series Models (SUTSE)

$\checkmark$ Different sampling intervals: cumulator variable

$\checkmark$ Optimal interpolation using the Kalman Filter and the Smoothing Algorithm 


\section{Modelling approach}

The basic model is of the Unobserved Component Model class known as the Basic Structural Model (Harvey 1989), that decomposes a set of time series in unobserved though meaningful components from an economic point of view (mainly trend, seasonal and irregular). The model is multivariate, and may be written as

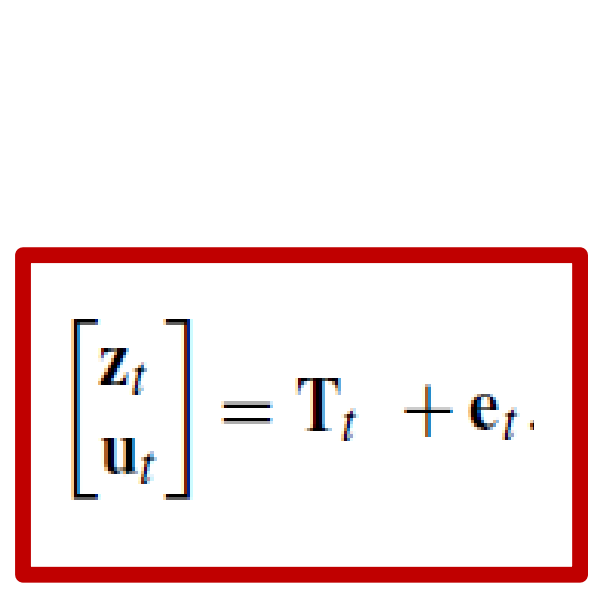

\begin{tabular}{|l|}
\hline $\begin{array}{l}\text { State-Space } \\
\text { representation }\end{array}$ \\
Trend: $\underline{\text { SRW }}$ \\
(no seasonal) \\
\hline
\end{tabular}

$$
\begin{aligned}
& \mathbf{x}_{t}=\Phi \mathbf{x}_{\mathbf{t}-1}+\mathbf{E w}_{\mathbf{t}} \\
& {\left[\begin{array}{l}
\mathbf{z}_{t} \\
\mathbf{u}_{t}
\end{array}\right]=\left[\begin{array}{l}
\mathbf{H} \\
\mathbf{H}^{u}
\end{array}\right] \mathbf{x}_{t}+\left[\begin{array}{l}
\boldsymbol{\epsilon}_{t} \\
\mathbf{v}_{t}
\end{array}\right]}
\end{aligned}
$$

where

$$
\begin{aligned}
\mathbf{w}_{t} & \sim N\left(0, \Sigma_{\mathbf{w}_{t}}\right), \quad \boldsymbol{\epsilon}_{t} \sim N\left(0, \Sigma_{\epsilon}\right), \\
\mathbf{v}_{t} & \sim N\left(0, \Sigma_{\mathbf{v}_{t}}\right) .
\end{aligned}
$$

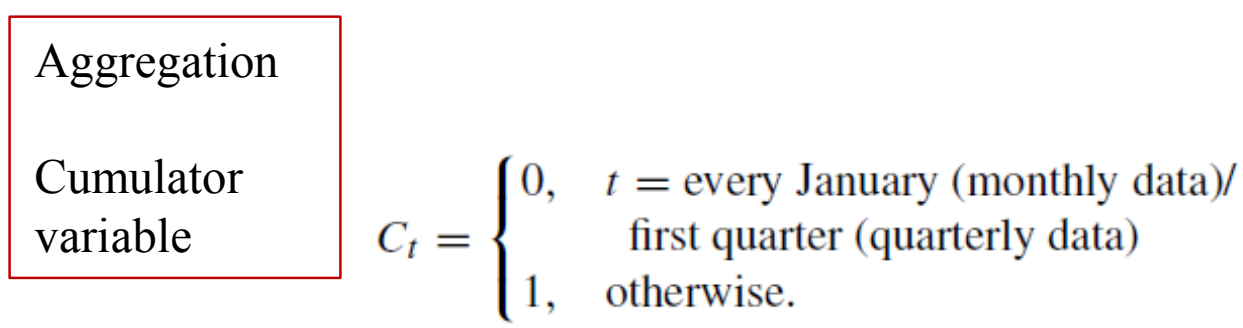

$\mathbf{z}_{t}$ : quarterly private consumption

Thus, the model turns out to be:

$\mathbf{u}_{t}$ : set of monthly indicators

$$
\begin{aligned}
& {\left[\begin{array}{l}
\mathbf{z}_{t} \\
\mathbf{x}_{t}
\end{array}\right]=\left[\begin{array}{ll}
C_{t} \otimes \mathbf{I} & \mathbf{H} \boldsymbol{\Phi} \\
\mathbf{0} & \boldsymbol{\Phi}
\end{array}\right]\left[\begin{array}{l}
\mathbf{z}_{t-1} \\
\mathbf{x}_{t-1}
\end{array}\right]+\left[\begin{array}{ll}
1 & \mathbf{H} \\
\mathbf{0} & \mathbf{E}
\end{array}\right]\left[\begin{array}{c}
\epsilon_{t} \\
\mathbf{w}_{t}
\end{array}\right]} \\
& \left\lceil\mathbf{z}_{t}\right\rceil=\left\lceil\begin{array}{ll}
\mathbf{I} & \mathbf{0}
\end{array} .\left\lceil\mathbf{z}_{t}\right\rceil_{+}\lceil\mathbf{0}\rceil \mathbf{v} .\right.
\end{aligned}
$$


Outline

1. Motivation

2. Literature review

3. The data

4. Modeling approach

5. The empirical exercise

6. Selection of results and conclusions 


\section{The empirical exercise}

- Real-time database

$\checkmark$ Different forecast origins (information sets) within each quarter: m1, m2, m3

- Full sample: (1995Q1) 2001Q1-2017Q4

- Out-of-sample evaluation over 2008Q1-2017Q4 [40 obs. per forecast origin x 3]

$\checkmark$ Quantitative: RMSEs

$\checkmark$ Quantitative: Diebold-Mariano

$\checkmark$ Qualitative: sign anticipation (Pesaran-Timmermann)

- First released QNA figure as reference [results qualitatively similar for "FINAL"]

- Benchmark (QRW): repeat quarterly growth rate (economic grounds) 


\section{Empirical exercise: real-time database}

\begin{tabular}{|c|c|c|c|c|c|c|}
\hline \multirow{3}{*}{$\begin{array}{r}\text { Information available at } \\
\text { nowcasting time... }\end{array}$} & \multicolumn{6}{|c|}{... $\mathrm{ml}$ (lst month of the quarter) } \\
\hline & \multicolumn{3}{|c|}{ Previous quarter } & \multicolumn{3}{|c|}{ Current quarter } \\
\hline & \begin{tabular}{c|} 
lst \\
month
\end{tabular} & $\begin{array}{c}\text { 2nd } \\
\text { month }\end{array}$ & $\begin{array}{c}\text { 3rd } \\
\text { month }\end{array}$ & $\begin{array}{c}\text { 1st } \\
\text { month }\end{array}$ & $\begin{array}{c}\text { 2nd } \\
\text { month }\end{array}$ & $\begin{array}{c}3 \mathrm{rd} \\
\text { month }\end{array}$ \\
\hline \multicolumn{7}{|l|}{ Private consumption (QNA) } \\
\hline \multicolumn{7}{|l|}{$\begin{array}{l}\text { Retail trade index } \\
\text { Services activity index }\end{array}$} \\
\hline \multicolumn{7}{|l|}{$\begin{array}{l}\text { PMI. Services } \\
\text { Consumers confidence index }\end{array}$} \\
\hline \multicolumn{7}{|l|}{$\begin{array}{l}\text { Credit cards - ATMs } \\
\text { Credit cards - POSs }\end{array}$} \\
\hline $\begin{array}{l}\text { Disagreement - consumption } \\
\text { Disagreement - inflation } \\
\text { Unemploymeny expectations } \\
\text { Economic policy uncertainty } \\
\text { Stock market volatility }\end{array}$ & & & & & & \\
\hline Google Trends & & & & & & \\
\hline
\end{tabular}

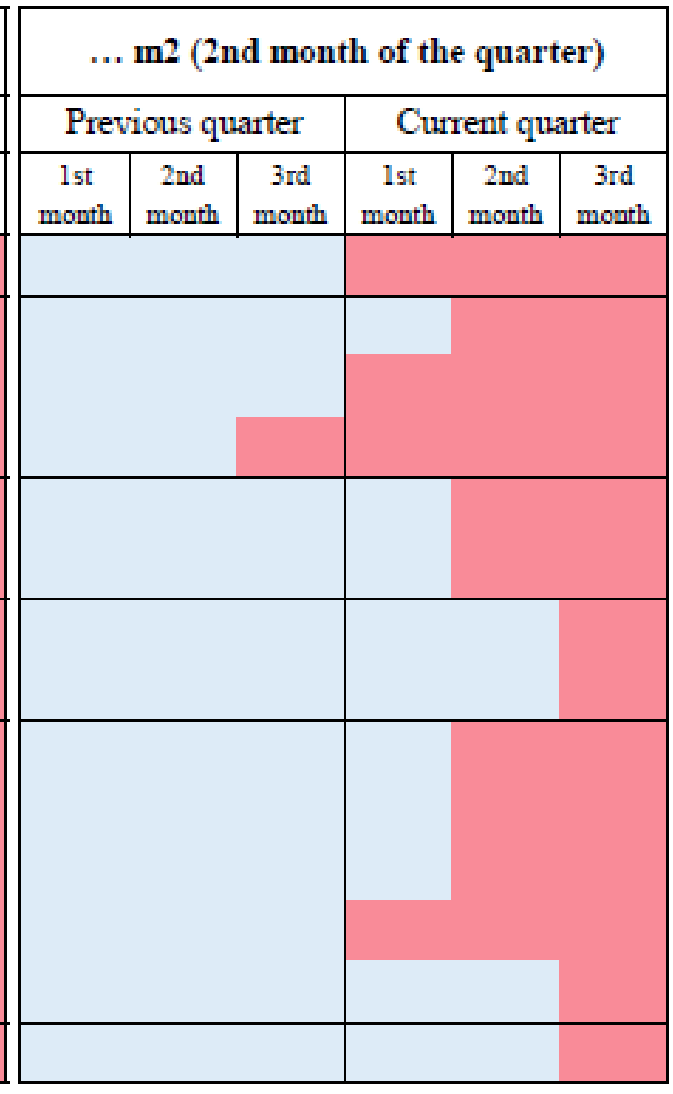

\begin{tabular}{|c|c|c|c|c|c|}
\hline \multicolumn{6}{|c|}{... m3 (3rd month of the quarter) } \\
\hline \multicolumn{3}{|c|}{ Previous quarter } & \multicolumn{3}{|c|}{ Current quarter } \\
\hline $\begin{array}{c}\text { lst } \\
\text { month }\end{array}$ & $\begin{array}{c}\text { 2nd } \\
\text { month }\end{array}$ & $\begin{array}{c}\text { 3rd } \\
\text { month }\end{array}$ & $\begin{array}{c}\text { 1st } \\
\text { month }\end{array}$ & $\begin{array}{c}\text { 2nd } \\
\text { month }\end{array}$ & $\begin{array}{c}\text { 3rd } \\
\text { month }\end{array}$ \\
\hline & & & & & \\
\hline & & & & & \\
\hline & & & & & \\
\hline & & & & & \\
\hline & & & & & \\
\hline & & & & & \\
\hline & & & & & \\
\hline & & & & & \\
\hline & & & & & \\
\hline & & & & & \\
\hline & & & & & \\
\hline
\end{tabular}


Outline

1. Motivation

2. Literature review

3. The data

4. Modeling approach

5. The empirical exercise

6. Selection of results and conclusions 


\section{- Quantitative measures of forecast accuracy: RMSEs relative to QRW}

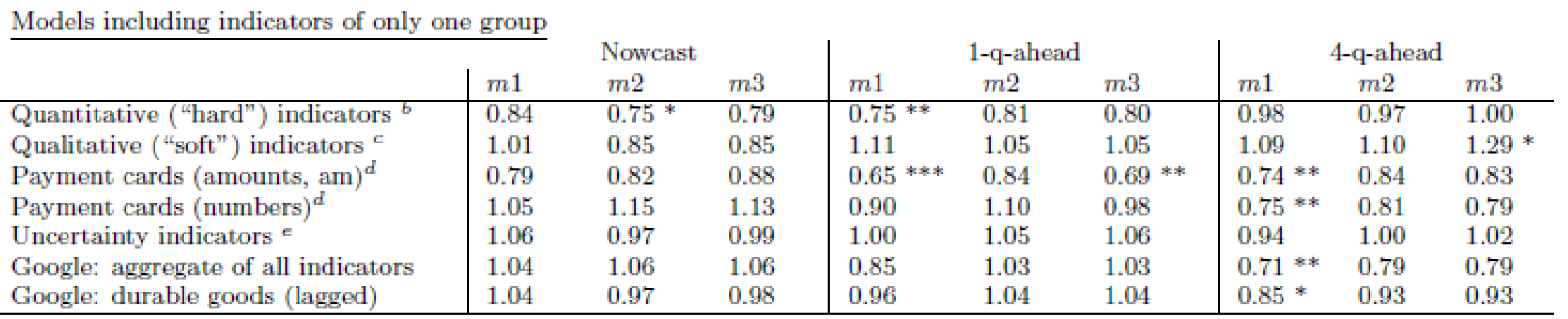

$\underline{\text { Models including indicators from different groups }}$

\begin{tabular}{|c|c|c|c|c|c|c|c|c|c|}
\hline & \multicolumn{3}{|c|}{ Nowcast } & \multicolumn{3}{|c|}{ 1-q-ahead } & \multicolumn{3}{|c|}{ 4-q-ahead } \\
\hline & $m 1$ & $m 2$ & $m 3$ & $m 1$ & $m 2$ & $m 3$ & $m 1$ & $m 2$ & $m 3$ \\
\hline Quantitative \& Qualitative & $0.69 * *$ & 0.78 & 0.77 & $0.67^{* * *}$ & $0.76^{*}$ & $0.72 *$ & $0.79^{*}$ & $0.82^{*}$ & $0.80^{*}$ \\
\hline Quantitative \& Payment cards (am) ${ }^{d}$ & 0.90 & 0.82 & 0.91 & $0.67 * * *$ & 0.79 & 0.78 & 0.86 & 0.89 & 0.91 \\
\hline Quantitative \& Uncertainty & 0.88 & 0.86 & 0.75 & $0.74 * *$ & 0.91 & 0.93 & $0.69 * *$ & 0.76 & 0.76 \\
\hline Quantitative \& Google (aggregate) & 0.85 & 0.76 & 0.77 & $0.81 *$ & 0.94 & 0.89 & $0.77 * *$ & $0.81 *$ & 0.82 \\
\hline Quantitative \& Google (durables) & 0.91 & 0.95 & 0.87 & $0.69 * *$ & 0.83 & 0.88 & $0.72 * *$ & $0.76 *$ & $0.77 *$ \\
\hline
\end{tabular}

\section{Combination of models}

\begin{tabular}{|c|c|c|c|c|c|c|c|c|c|}
\hline & \multicolumn{3}{|c|}{ Nowcast } & \multicolumn{3}{|c|}{ 1-q-ahead } & \multicolumn{3}{|c|}{ 4-q-ahead } \\
\hline & $m 1$ & $m 2$ & $m 3$ & $m 1$ & $m 2$ & $m 3$ & $m 1$ & $m 2$ & $m 3$ \\
\hline All models ${ }^{f}$ & $0.66^{* *}$ & $0.71^{* *}$ & $0.69^{* *}$ & $0.68^{* * *}$ & $0.77^{*}$ & $0.68^{* *}$ & $0.73^{* *}$ & $0.78^{*}$ & $0.78^{*}$ \\
\hline Hard \& Payment cards (am) ${ }^{d}$ & $0.62 * *$ & $0.69 * *$ & $0.71 * *$ & $0.53^{* * *}$ & $0.69^{* *}$ & $0.52 * * *$ & $0.79 *$ & 0.86 & 0.84 \\
\hline Hard, Payment cards (am) $)^{d} \&$ Soft & $0.65 * *$ & $0.67 * *$ & $0.67 * *$ & $0.68 * * *$ & $0.74 * *$ & $0.59 * * *$ & $0.83 *$ & 0.89 & 0.92 \\
\hline Hard \& Soft & $0.68 * *$ & $0.66^{* *}$ & $0.66 * *$ & $0.77^{* *}$ & $0.75 * *$ & $0.69 * *$ & 0.91 & 0.94 & 1.02 \\
\hline Hard \& Google (durables) & $0.77 * *$ & $0.78^{* *}$ & $0.76 * *$ & $0.74^{* * *}$ & 0.83 & $0.78 *$ & 0.85 & 0.91 & 0.90 \\
\hline
\end{tabular}


- Quantitative measures of forecast accuracy: pairwise relative RMSEs \& DM-tests

\begin{tabular}{|c|c|c|c|c|c|c|c|c|c|}
\hline & {$[2]$} & {$[3]$} & {$[4]$} & {$[5]$} & {$[6]$} & [7] & [8] & {$[9]$} & {$[10]^{g}$} \\
\hline Q-Random Walk [1] & 1.19 & 0.99 & 1.26 & 0.95 & 0.94 & 0.96 & $1.52^{* *}$ & $1.62^{* *}$ & $1.55^{* *}$ \\
\hline Quantitative $^{a}[2]$ & - & 0.83 & 1.06 & $0.80^{*}$ & $0.79^{*}$ & 0.81 & $1.27^{*}$ & $1.35^{* *}$ & $1.30^{*}$ \\
\hline Qualitative $^{b}[3]$ & - & - & $1.27^{*}$ & 0.96 & 0.95 & 0.97 & $1.53^{* *}$ & $1.63^{* *}$ & $1.56^{* * *}$ \\
\hline Payment cards ${ }^{c}[4]$ & - & - & - & $0.75^{* *}$ & $0.74^{*}$ & 0.76 & 1.20 & $1.28^{*}$ & $1.23^{*}$ \\
\hline Uncertainty $^{d}[5]$ & - & - & - & - & 0.99 & 1.01 & 1. $60^{* * *}$ & $1.70^{* * *}$ & $1.63^{* * *}$ \\
\hline Google $^{e}[6]$ & - & - & - & - & - & 1.03 & $1.62^{* * *}$ & $1.72^{* * *}$ & $1.65^{* * *}$ \\
\hline Comb: All models $f[7]$ & - & - & - & - & - & - & $1.58^{* * *}$ & $1.68 * *$ & $1.61^{* * *}$ \\
\hline Comb: Quant. ${ }^{a} \&$ Cards $^{c}[8]$ & - & - & - & - & - & - & - & 1.06 & 1.02 \\
\hline Comb: Quant. ${ }^{a} \&$ Qual. ${ }^{b}[9]$ & - & - & - & - & - & - & - & - & 0.96 \\
\hline
\end{tabular}

\begin{tabular}{|c|c|c|c|c|c|c|c|c|c|}
\hline & {$[2]$} & [3] & {$[4]$} & [5] & {$[6]$} & {$[7]$} & [8] & {$[9]$} & {$[10]^{g}$} \\
\hline Q-Random Walk [1] & $1.33^{*}$ & 1.18 & 1.23 & 0.87 & 1.03 & 1.03 & $1.41^{* * *}$ & $1.45^{* 3 *}$ & $1.48^{3 * * *}$ \\
\hline Quantitative $^{a}[2]$ & - & 0.89 & 0.92 & $0.65 * *$ & $0.77^{*}$ & 0.77 & 1.06 & 1.09 & 1.12 \\
\hline Qualitative $^{b}[3]$ & - & - & 1.04 & $0.73^{* *}$ & 0.87 & 0.87 & 1.19 & 1.22 & $1.26^{* *}$ \\
\hline Payment cards ${ }^{c}[4]$ & - & - & - & $0.71^{* *}$ & 0.84 & 0.84 & 1.15 & 1.18 & $1.21^{*}$ \\
\hline Uncertainty $^{d}[5]$ & - & - & - & - & 1.18 & 1.18 & $1.62^{* * *}$ & $1.66^{* * *}$ & $1.71^{* * *}$ \\
\hline Google $^{e}[6]$ & - & - & - & - & - & 1.00 & $1.37^{* *}$ & $1.41^{* *}$ & $1.44^{* *}$ \\
\hline Comb: All models ${ }^{f}[7]$ & - & - & - & - & - & - & $1.37^{* *}$ & $1.41^{* *}$ & $1.45^{* *}$ \\
\hline Comb: Quant. ${ }^{a} \&$ Cards $^{c}[8]$ & - & - & - & - & - & - & - & 1.03 & 1.05 \\
\hline Comb: Quant. ${ }^{a} \&$ Qual. ${ }^{b}[9]$ & - & - & - & - & - & - & - & - & 1.03 \\
\hline
\end{tabular}

\begin{tabular}{|c|c|c|c|c|c|c|c|c|c|}
\hline & {$[2]$} & {$[3]$} & {$[4]$} & {$[5]$} & {$[6]$} & {$[7]$} & [8] & {$[9]$} & {$[10]^{g}$} \\
\hline Q-Random Walk [1] & 1.27 & 1.18 & 1.14 & 0.89 & 1.01 & 1.02 & $1.46^{* *}$ & $1.42^{* *}$ & $1.49^{* *}$ \\
\hline Quantitative $^{a}[2]$ & - & 0.93 & 0.89 & $0.70^{* *}$ & 0.79 & 0.81 & 1.15 & 1.11 & 1.17 \\
\hline Qualitative $^{b}[3]$ & - & - & 0.97 & $0.75^{* *}$ & 0.85 & 0.87 & 1.24 & 1.20 & $1.26^{* *}$ \\
\hline Payment cards ${ }^{c}[4]$ & - & - & - & $0.78^{*}$ & 0.88 & 0.90 & $1.28^{*}$ & $1.24^{* *}$ & $1.30^{* *}$ \\
\hline Uncertainty $^{d}[5]$ & - & - & - & - & 1.13 & 1.15 & $1.64^{* * *}$ & $1.60^{* * *}$ & $1.67^{* * *}$ \\
\hline Google $^{e}[6]$ & 一 & 一 & 一 & - & - & 1.02 & $1.45^{* *}$ & $1.41^{*}$ & $1.48 * *$ \\
\hline Comb: All models $f[7]$ & - & - & - & - & - & - & $1.42^{* *}$ & $1.38^{*}$ & $1.45^{* *}$ \\
\hline Comb: Quant. ${ }^{a} \&$ Cards $^{c}[8]$ & - & - & - & - & - & - & - & 0.97 & 1.02 \\
\hline Comb: Quant. ${ }^{a} \&$ Qual. ${ }^{b}[9]$ & - & - & - & - & - & - & - & - & 1.05 \\
\hline
\end{tabular}


- Better forecast performance in "good times" than in "bad times"

- Performance in "good and bad times": change in relative behavior (cards, others)

Recession (2008-2012) vs Full sample Relative RMSE

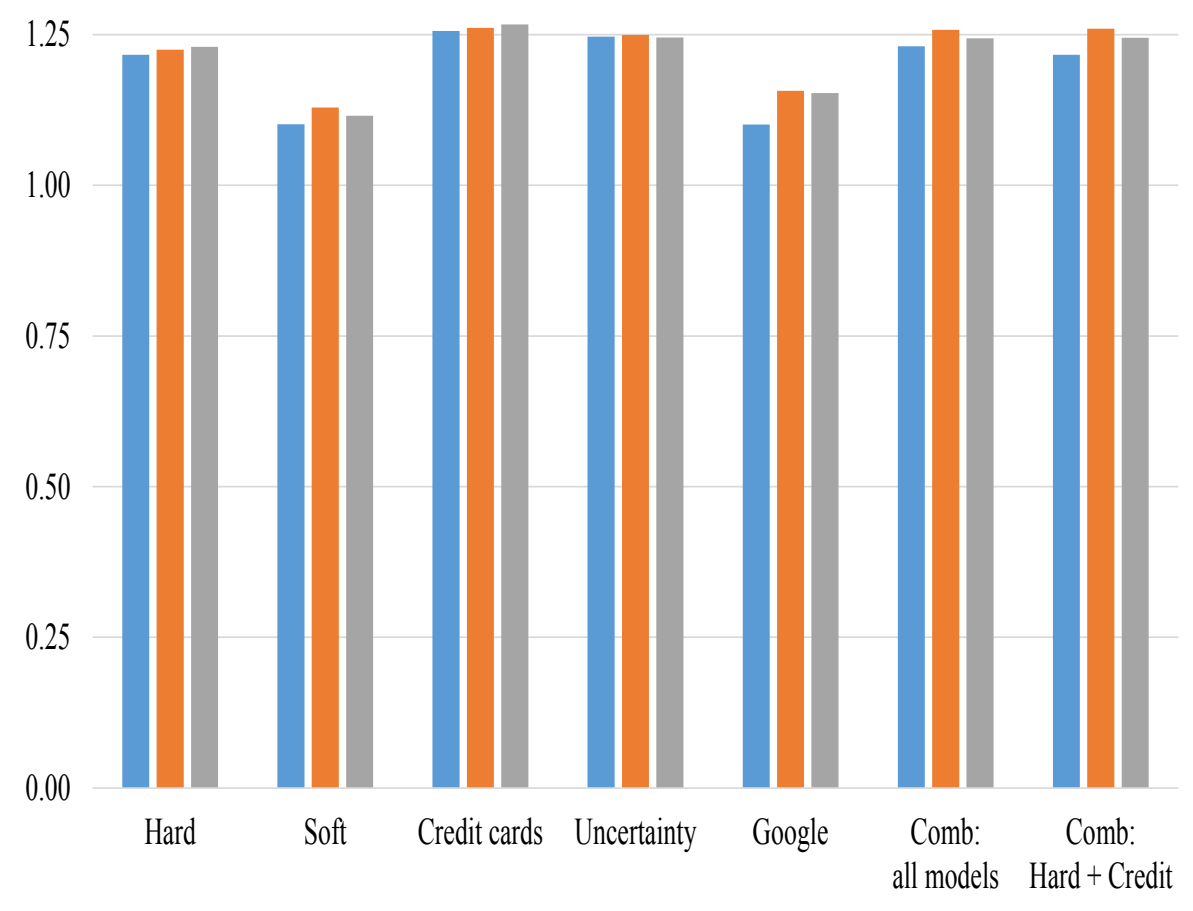

$\square \mathrm{m} 1=\mathrm{m} 2 \square \mathrm{m} 3$

\section{Expansion (2013-2016) vs Full sample} Relative RMSE

1.50

1.25

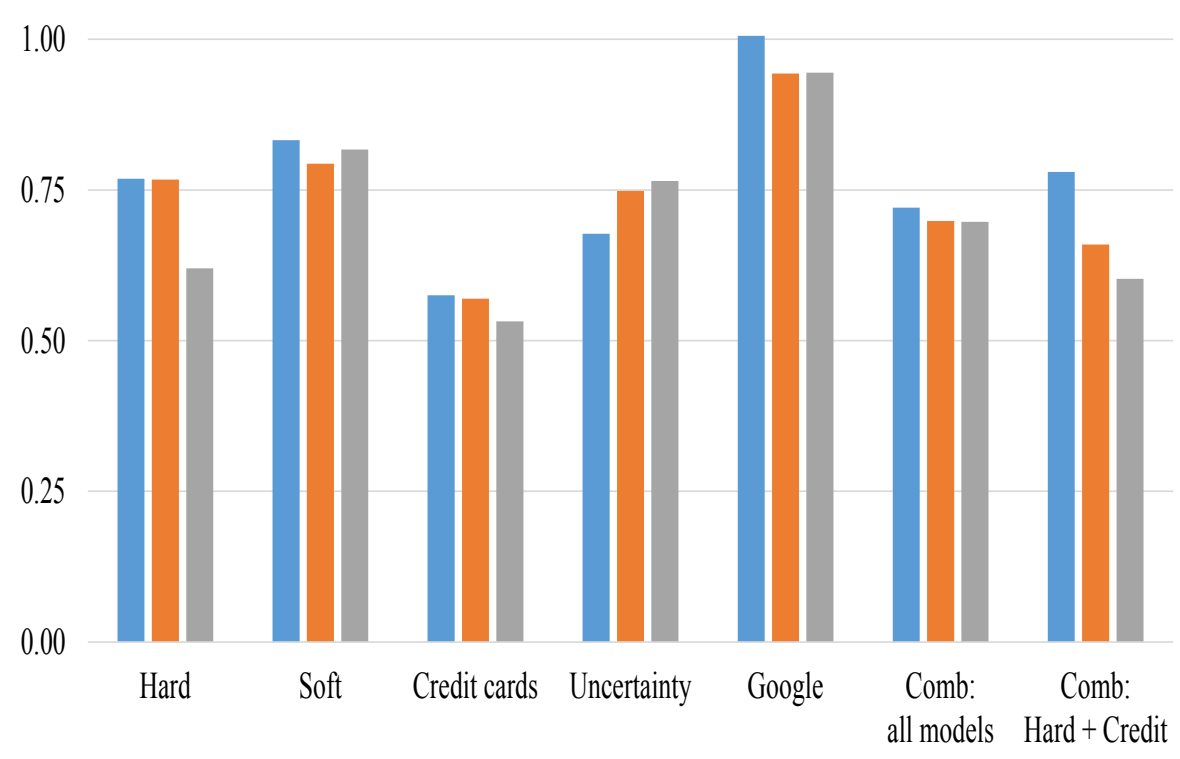

$\square \mathrm{m} 1 \square \mathrm{m} 2 \square \mathrm{m} 3$ 


\section{- Qualitative measures of forecast accuracy: Pessaran-Timmerman tests}

$\underline{\text { Models including indicators of only one group }}$

\begin{tabular}{|c|c|c|c|c|c|c|c|c|c|}
\hline & $m 1$ & $\begin{array}{l}\text { Nowcast } \\
m 2\end{array}$ & $m 3$ & $m 1$ & $\begin{array}{l}\text { 1-q-ahead } \\
m 2\end{array}$ & $m 3$ & $m 1$ & $\begin{array}{l}\text { 4-q-ahead } \\
m 2\end{array}$ & $m 3$ \\
\hline Quarterly Random Walk & $0.70^{* *}$ & $0.80^{* * *}$ & $0.80^{* * *}$ & 0.64 & $0.69^{* *}$ & $0.69^{* *}$ & 0.50 & 0.56 & 0.56 \\
\hline Quantitative ("hard") indicators ${ }^{b}$ & $0.78^{* * *}$ & $0.78^{* * *}$ & $0.73^{* * *}$ & $0.77^{* * *}$ & $0.82^{* * *}$ & $0.77^{* * *}$ & $0.64^{* * *}$ & $0.69^{* * *}$ & $0.67^{* * *}$ \\
\hline Qualitative ("soft") indicators ${ }^{c}$ & $0.78^{* * *}$ & $0.85^{* * *}$ & $0.83^{* * *}$ & $0.69 * *$ & $0.79^{* * *}$ & $0.77^{* * *}$ & 0.50 & 0.61 & 0.53 \\
\hline Payment cards (amounts,am) ${ }^{d}$ & $0.78^{* * *}$ & $0.78^{* * *}$ & $0.80^{* * *}$ & $0.74^{* * *}$ & $0.79^{* * *}$ & $0.85 * * *$ & 0.56 & 0.58 & 0.61 \\
\hline Payment cards (numbers) ${ }^{d}$ & $0.75^{* * *}$ & $0.75^{* * *}$ & $0.75^{* * *}$ & $0.72^{* *}$ & $0.69^{* *}$ & $0.77^{* * *}$ & 0.50 & $0.69^{* *}$ & $0.67^{* *}$ \\
\hline Uncertainty indicators $e$ & $0.73^{* * *}$ & $0.78^{* * *}$ & $0.78 * * *$ & $0.67^{* *}$ & $0.72^{* * *}$ & $0.69^{* *}$ & 0.50 & 0.56 & 0.56 \\
\hline Google: aggregate of all indicators & 0.40 & $0.80^{* * *}$ & $0.80^{* * *}$ & 0.26 & 0.51 & 0.41 & 0.25 & 0.28 & 0.44 \\
\hline Google: durable goods (lagged) & $0.73^{* * *}$ & $0.73^{* * *}$ & $0.73^{* * *}$ & $0.69^{* *}$ & $0.72^{* * *}$ & $0.72^{* * *}$ & 0.53 & 0.58 & 0.58 \\
\hline
\end{tabular}

$\underline{\text { Models including indicators from different groups }}$

\begin{tabular}{|c|c|c|c|c|c|c|c|c|c|}
\hline & \multirow[b]{2}{*}{$m 1$} & \multicolumn{2}{|l|}{ Nowcast } & \multicolumn{3}{|c|}{ 1-q-ahead } & \multicolumn{3}{|c|}{ 4-q-ahead } \\
\hline & & $m 2$ & $m 3$ & $m 1$ & $m 2$ & $m 3$ & $m 1$ & $m 2$ & $m 3$ \\
\hline Quantitative \& Qualitative & $0.78^{* * *}$ & $0.78^{* * 3}$ & $0.78^{* 3 * 3}$ & $0.77^{* 3 *}$ & $0.87^{* 3 *}$ & $0.85^{* 3 *}$ & $0.64^{3 * * * 3}$ & $0.67^{* 3 *}$ & $0.67^{\text {*3*3. }}$ \\
\hline Quantitative \& Payment cards $(\mathrm{am})^{d}$ & $0.78^{* * *}$ & $0.83^{* * *}$ & $0.78 * * *$ & $0.74^{* * *}$ & $0.77^{* * *}$ & $0.77^{* * *}$ & $0.61^{* *}$ & $0.67^{* * *}$ & $0.61^{* *}$ \\
\hline Quantitative \& Uncertainty ${ }^{e}$ & $0.75 * * *$ & $0.73^{* * *}$ & $0.75 * * *$ & $0.79 * * *$ & $0.74^{* * *}$ & $0.74^{* * * *}$ & 0.56 & 0.61 & 0.61 \\
\hline Quantitative \& Google (aggregate) & $0.78 * * *$ & $0.78 * * *$ & $0.70^{* * *}$ & $0.74^{* * *}$ & $0.77^{* * *}$ & $0.82^{* * *}$ & 0.58 & 0.58 & $0.64^{* *}$ \\
\hline Quantitative \& Google (durables) & $0.78^{* * *}$ & $0.78^{* * * *}$ & $0.78 * * *$ & $0.77^{* * *}$ & $0.82^{* * *}$ & $0.79^{* * *}$ & $0.64^{* *}$ & 0.61 & $0.61^{*}$ \\
\hline
\end{tabular}

Combination of models

\begin{tabular}{|c|c|c|c|c|c|c|c|c|c|}
\hline \multirow[t]{2}{*}{ 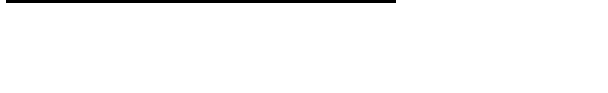 } & \multicolumn{3}{|c|}{ Nowcast } & \multicolumn{3}{|c|}{ 1-q-ahead } & \multicolumn{3}{|c|}{ 4-q-ahead } \\
\hline & $m 1$ & $m 2$ & $m 3$ & $m 1$ & $m 2$ & $m 3$ & $m 1$ & $m 2$ & $m 3$ \\
\hline All models $f$ & $0.88^{* * *}$ & $0.83^{* * *}$ & $0.78^{* * *}$ & $0.74^{* * *}$ & $0.85^{* * *}$ & $0.85^{* * *}$ & 0.56 & 0.58 & $0.67^{* * * *}$ \\
\hline Hard \& Payment cards (am) ${ }^{d}$ & $0.83^{* * *}$ & $0.78^{* * *}$ & $0.78 * * *$ & $0.85 * * *$ & $0.87 * * *$ & $0.85^{* * *}$ & $0.61^{*}$ & $0.69 * * *$ & $0.69^{* * *}$ \\
\hline Hard, Payment cards (am) $)^{d} \&$ Soft & $0.83^{* * *}$ & $0.85 * * *$ & $0.78 * * *$ & $0.74 * * *$ & $0.82 * * *$ & $0.87^{* * *}$ & 0.53 & $0.61^{*}$ & $0.67^{* *}$ \\
\hline Hard \& Soft & $0.83^{* * *}$ & $0.80^{* * *}$ & $0.80^{* * *}$ & $0.74^{* * *}$ & $0.79^{* * *}$ & $0.82^{* * *}$ & 0.50 & $0.64^{* *}$ & 0.58 \\
\hline Hard \& Google (durables) & $0.78^{* * *}$ & $0.78^{* * *}$ & $0.75^{* * *}$ & $0.77^{* * *}$ & $0.77^{* * *}$ & $0.79^{* * *}$ & 0.56 & $0.58^{*}$ & $0.61^{* *}$ \\
\hline
\end{tabular}


- Summing up:

$\checkmark$ "Traditional hard" indicators tend to dominate the nowcasting race

$\checkmark$ But credit-debit cards perform similarly in many dimensions, and work quite well combined with "hard"

$\checkmark$ The other "new" sources (Google, Uncertainty) and "Soft" indicators add value...

... when combined

... at longer forecast horizons (expectations, preparations)

$\checkmark$ "New" indicators (Google, Credit Cards) may also be add more value if used at a higher frequency (e.g. weekly data) 
THANKS FOR YOUR ATTENTION 